\title{
Optimization of Surface Properties of Shot Peened TI6AL4V Alloy
}

\author{
Y. YildirAN ${ }^{a, *}$, E. $\operatorname{AvCU}^{b}$, T. SinMAZÇELIK ${ }^{a}$
}

${ }^{a}$ Kocaeli University, Dept. Mech. Eng., 41285 Izmit, Turkey

${ }^{b}$ Kocaeli University, Ford Otosan İhsaniye Automotive Vocational School, 41680 Kocaeli, Turkey

As an important surface treatment method, shot peening (SP) is widely used in automotive and aerospace industries in order to improve surface properties. In the present study SP was performed on the $\alpha-\beta$ titanium alloy Ti6Al4V under various parameters (particle impingement angle, particle acceleration pressure and particle size) by using a specially designed shot peening test rig. It is aimed to optimize surface roughness and hardness of the shot peened Ti6Al4V alloy under various parameters. In order to achieve this goal shot peened samples were investigated in detail by using a non-contact laser optical profilometer and surface hardness of the samples was measured by using a micro-hardness instrument. The surface roughness values, 3D surface morphologies and micro-hardness of the samples were obtained and examined. The results show that particle impingement angle, particle acceleration pressure and particle size dramatically affect the surface properties of the Ti6Al4V alloy.

DOI: $10.12693 /$ APhysPolA.127.984

PACS: 62.20.Qp, 81.65.-b, 81.05.Bx, 68.35.bd

\section{Introduction}

Shot peening is a cold working process that involves the bombardment of spherical balls against the surface of components, thus it causes high plastic deformation on the surface of materials [1-3]. Shot peening (SP) is an important technology of mechanical treatment of surfaces, which modifies the elastic residual stress distribution of the surface, increases surface hardness, produces a higher near-surface dislocation density. It is used for various components such as railway and automobile leaf springs, helical springs of all types, gears, axle bearings, crankshafts, pneumatic drills, milling cutters, connecting rods, coil springs, cylinder blocks, valve springs, washers, etc. $[2-5]$.

Titanium alloys (specifically Ti6Al4V alloy) find extensive use in aerospace, automotive and biomedical applications due to their good mechanical, chemical and physical properties, such as high strength to weight ratio, high toughness, low density and excellent corrosion resistance [6-9]. The topography of roughened substrates plays a beneficial role in coating adhesion, and in varied phenomena which can influence adhesion, such as droplet impact, wetting and solidification, thus providing the possibility of SP application in many fields $[4,10,11]$. This paper presents experimental data concerning the effect of shot size, shot acceleration pressure and impact angle on the surface roughness and surface hardness of Ti6Al4V alloy, which is important for various applications.

*corresponding author; e-mail: yaseminyildiran89@gmail.com

\section{Materials and methods}

Ti6Al4V Grade 5 (R56400) with the following chemical composition (mass \%): C 0.8, Fe 0.25, N 0.05, O 0.20, $\mathrm{Al} 5.50-6.75$, V 3.5-4.5, H 0.015 , was used as substrate material in this study. Rectangular plate specimens (40x $40 \mathrm{~mm}$ ) with a thickness of $3 \mathrm{~mm}$ were cut from the titanium alloy. Mechanical and physical properties of Ti6Al4V samples are given in Table I.

TABLE I

Mechanical and physical properties of Ti6Al4V samples.

\begin{tabular}{c|c}
\hline \hline \multicolumn{2}{c}{ Mechanical Properties } \\
\hline Ultimate Strength & $896 \mathrm{MPa}$ \\
\hline Yield Strength & $827 \mathrm{MPa}$ \\
\hline \multicolumn{2}{c}{ Physical Properties } \\
\hline Density & $4.43 \mathrm{~g} / \mathrm{cm}^{3}$ \\
\hline Melting Point Approx. & $1650{ }^{\circ} \mathrm{C}$
\end{tabular}

The shot peening process was performed by means of a direct pressure in specially designed shot peening system under the conditions listed in Table II. The shot particles used in this investigation were steel shots with the following chemical composition (mass \%): $\mathrm{C}$ 0.85-1.20, Mn 0.60-1.20, Si 0.40, S 0.05, P 0.05.

TABLE II

Shot peening operation parameters.

\begin{tabular}{c|c}
\hline \hline Shot particle diameter [mm] & $0.20,0.60$ \\
\hline Acceleration pressure [bar] & 2,4 \\
\hline Impingement angle $\left[{ }^{\circ}\right]$ & 75,90 \\
\hline Peening time $[\mathrm{s}]$ & 10 \\
\hline Nozzle distance $[\mathrm{mm}]$ & 20
\end{tabular}


The surface roughness and morphology of the shot peened samples were measured by a 3D optical profilometer (Nanovea PS50), thus the effects of the shot peening operation parameters on the surface roughness and $3 \mathrm{D}$ surface topographies of $\mathrm{Ti} 6 \mathrm{Al} 4 \mathrm{~V}$ were studied. The micro-hardness of the samples was measured by a Digital Micro-hardness Tester (Metkon Duroline M) with an experimental force of $0.1 \mathrm{~N}$ and a loading time of $5 \mathrm{~s}$. Ten tests for each sample were carried out and then the average micro hardness values for each sample were calculated.

\section{Results and discussions}

\subsection{Investigation of surface roughness and morphology}

In Fig. 1 arithmetic average surface roughness values of the Ti6Al4V alloy as functions of shot impingement angle (Fig. 1a), shot acceleration pressure (Fig. 1b) and shot size (Fig. 1c) are given. The surface roughness of the Ti6Al4V alloy changes as a function of the shot impingement angle. The increase of shot impingement angle causes the increase of surface roughness values as seen in Fig. 1a. As can be seen in Fig. 1 the surface roughness of Ti6Al4V alloy increases with the increase of the shot size. It was reported, that the increase of shot size causes the increase of surface roughness [1]. Moreover the roughness increases also with the increase of the shot acceleration pressure, as can be clearly seen in Fig. 1 .

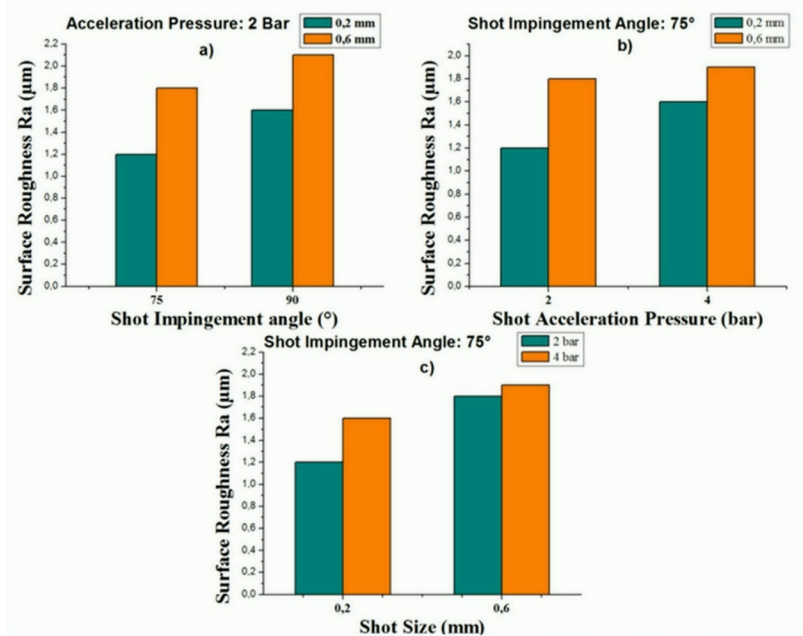

Fig. 1. Arithmetic average surface roughness values of Ti6Al4V alloy as functions of a) shot impingement angle, b) shot acceleration pressure, c) shot size.

In Fig 2. the 3D surface morphologies of the shot peened Ti6Al4V samples are given in order to understand the shot peening mechanisms and the effects of peening parameters. The surface morphology is specifically varied with the shot acceleration pressure. The height of peaks and deepness of holes are increased sharply with the increasing pressure. On the other hand, shot size has also affected the morphology of the surface. The plastic deformation caused by peening is increased with the increase of the shot size. These results confirm and correlate with the surface roughness variation under various parameters.
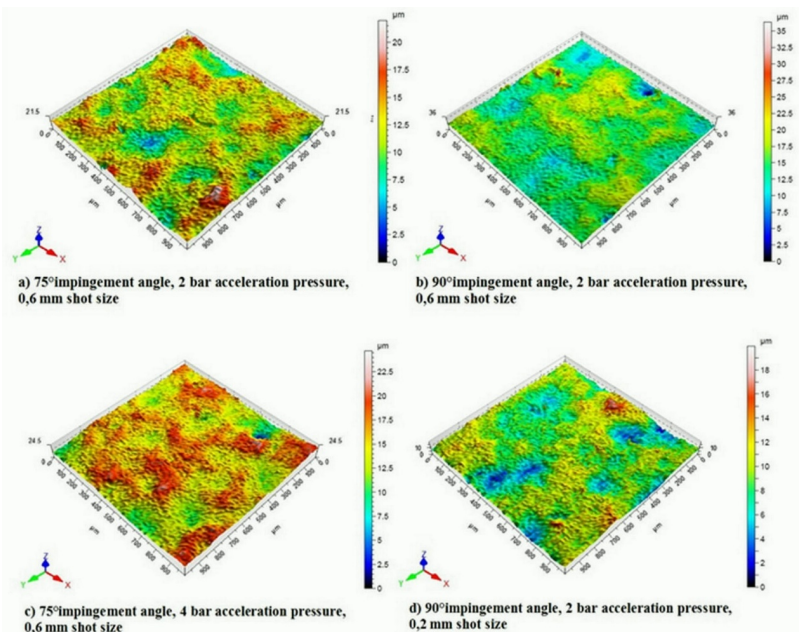

Fig. 2. 3D surface morphologies of the Ti6Al4V samples.

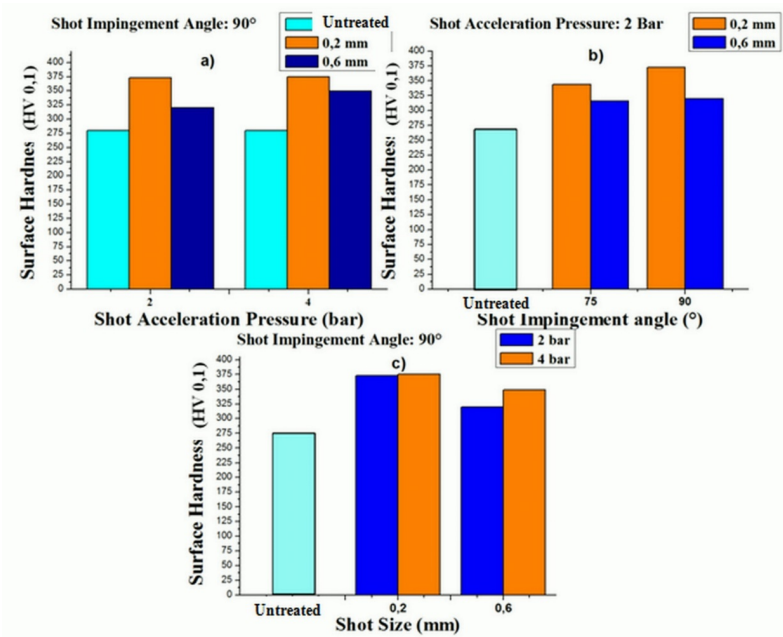

Fig. 3. Arithmetic average surface hardness values of Ti6Al4V alloy as functions of a) shot acceleration pressure, b) shot impingement angle, c) shot size.

\subsection{Investigation of surface hardness}

In Fig. 3 arithmetic average surface hardness values of the Ti6Al4V alloy as functions of shot acceleration pressure (Fig. 3a), shot impingement angle (Fig. 3b) and shot size (Fig. 3c) are given. Compared to the untreated sample, shot peening process caused an increase of the surface hardness, as expected. Although, the increase in hardness has altered significantly, depending on peening parameters. The increases in shot impingement angle, size and acceleration cause an increase of hardness. Among all considered parameters, the shot size has the most dominant effect on the hardness of the peened samples. 


\section{Conclusions}

The conclusions of the present study are summarized below,

1. The surface roughness of the samples increases with the increase of shot particle size and acceleration pressure. Three-dimensional surface morphologies of shot peened samples revealed plastic deformations under various shot peening parameters.

2. The surface hardness of the shot peened samples increases compared to untreated sample. It is concluded that shot particle size, acceleration pressure and impingement angle dramatically affect the surface hardness of titanium alloy. The increase of the acceleration pressure and impingement angle cause an increase in surface hardness of the peened samples, while the increase of the shot size causes the decrease of surface hardness of the peened samples.

3. Shot impingement angle, size and acceleration pressure have to be adjusted precisely, particularly in order to optimize the surface hardness of shot peened components. Hence, the findings of this study can be used in optimization of surface roughness and hardness of the shot peenend components.

\section{References}

[1] S.B. Mahagaonkar, P.K. Brahmankar, C.Y. Seemikeri, International Journal of Fatigue 31, 693 (2009).

[2] L. Xie, C.Jiang, W. Lu, Q. Feng, X. Wu, Surface and Coatings Technology 206, 511 (2011).

[3] O. Unal, R. Varol, Applied Surface Science 290, 40 (2014).

[4] S. Bagherifard, R. Ghelichi, M. Guagliano, Applied Surface Science 258, 6831 (2012).

[5] P.M. George, N. Pillai, N. Shah, Journal of Materials Processing Technology 153-154, 925 (2004).

[6] M. Herrero-Climent, P. Lázaro, J.V. Rios, S. Lluch, M. Marqués, J. Guillem-Martí, F.J. Gil, J. Mater Sci: Mater. Med. 24, 2047 (2013).

[7] E. Avcu, S. Fidan, Y. Yıldıran, T. Sınmazçelik, Tribology - Materials, Surfaces and Interfaces 7, 201 (2013).

[8] T.M. Manhabosco, S.M. Tamborim, C.B. dos Santos, I.L. Müller, Corrosion Science 53, 1786 (2011).

[9] C. Martini, L. Ceschini, Tribology International 44, 297 (2011)

[10] B. Arifvianto, Suyitno, M. Mahardika, P. Dewo, P.T. Iswanto, U.A. Salim, Materials Chemistry and Physics 125, 418 (2011).

[11] S.M. Hassani-Gangaraj, A. Moridi, M. Guagliano, A. Ghidini, M. Boniardi, International Journal of Fatigue 62, 67 (2014). 